\title{
Association between stroke and psychosis across four nationally representative epidemiological studies
}

\author{
Authors: \\ Vaughan Bell ${ }^{1,2}$ \\ William Tamayo-Agudelo ${ }^{1,3}$ \\ Grace Revill $^{1}$ \\ David Okai ${ }^{4}$ \\ Norman Poole ${ }^{5}$
}

\begin{abstract}
Affiliations:
1. Research Department of Clinical, Educational and Health Psychology, University College London, UK

2. South London and Maudsley NHS Foundation Trust, London, UK

3. Universidad Cooperativa de Colombia, Medellín, Colombia

4. Department of Neuropsychiatry, South London and Maudsley NHS Foundation Trust, London, UK

5. Department of Neuropsychiatry, South West London and St George's Mental Health NHS Trust, London, UK.
\end{abstract}

\section{Corresponding Author:}

Dr Vaughan Bell (Vaughan.Bell@ucl.ac.uk) 


\section{Abstract}

Background: Both stroke and psychosis are independently associated with high levels of disability. However, psychosis in the context of stroke has received remarkably little interest from clinicians and researchers. To date there are currently no population studies on their joint prevalence and association.

Methods: We estimated the prevalence of i) probable psychosis in stroke and, ii) stroke in probable psychosis using four nationally representative cross-sectional psychiatric epidemiological studies: two from high-income countries (United Kingdom and United States) and two from middle-income countries (Chile and Colombia) and, subsequently, a combined dataset from all four countries. We also tested the statistical association between stroke and psychosis using single and multi-level regression models to estimate the unadjusted association between stroke and psychosis, and the association adjusted for potential demographic confounders.

Results: The prevalence of probable psychosis in stroke ranged from 1.05\% [95\% CIs 0.03 5.73] in Chile, to $13.92 \%$ [95\% CIs 7.16 - 23.55] in Colombia, with the prevalence from the combined countries dataset estimated at 3.81\% [95\% CIs 2.34 - 5.82]. Stroke in probable psychosis ranged from 2.18\% [95\% CIs 1.09 - 3.86] in Colombia, to 16.67\% [95\% CIs 6.37 32.81] in the US, with the combined countries prevalence estimated at 3.15\% [95\% CIs 1.94 4.83]. Estimates for the adjusted association between stroke and probable psychosis ranged from an $\mathrm{OR}=1.11$ [95\% CIs $0.15-8.26$ ] in the UK to an OR $=6.22$ in the US [95\% CIs 2.52 - 15.35] with the adjusted association from the combined dataset estimated at $\mathrm{OR}=3.32$ [95\% CIs 2.05 - 5.38]. Larger prevalences and associations were associated with larger confidence intervals and we suggest the smaller estimates are likely to be more accurate. We also examined the association between stroke and paranoia, hallucinated voices, and thought passivity delusion, and although we found significant variation in the reliability and strength of association across countries, all three psychotic symptoms were associated with stroke in the unadjusted and adjusted analyses in the combined countries dataset.

Conclusions: There are high rates of association between psychosis and stroke, meaning there is likely a high clinical need group who are under-researched and may be poorly served by existing services. Notably, stroke is a known risk factor for psychosis, and psychosis and antipsychotic treatment for psychosis are known risk factors for stroke, meaning causality is likely to be bidirectional and treatment pathways should be integrated across traditional service boundaries. 


\section{Introduction}

Psychosis in the context of stroke has received remarkably little interest from clinicians and researchers despite both conditions being major causes of disability. Stroke and active psychosis are independently considered to cause some of the highest levels of disability among health conditions (Charlson et al., 2018; Johnson et al., 2019), meaning their combination is likely to result in severely debilitating outcomes for affected individuals. To add to the complexity, initial evidence suggests that the most common treatment for psychosis in stroke-affected individuals, antipsychotics, may increase mortality in this patient group (Su et al., 2021).

Despite clear clinical need, the first systematic review, and indeed the first review, dedicated to stroke and psychosis was only published in 2018 and focused specifically on poststroke psychosis (Stangeland et al., 2018). It is important to note that the association between stroke and psychosis extends beyond cases of poststroke psychosis and also includes those who have a preceding history of psychosis and are later affected by stroke. Indeed, people with a diagnosis of schizophrenia have increased risk factors for stroke (Bresee et al., 2010), and are at higher risk of stroke (Li et al., 2014) and recurrent stroke (Fleetwood et al., 2021). The main treatment for psychosis, antipsychotic medication, raises the risk of stroke with strong evidence for the role of metabolic syndrome (Nielsen et al., 2021) and likely alternative mechanisms also including platelet aggregation, orthostatic hypotension and cardiac arrthymias (Marto et al., 2021). Studies on predictors of cardiovascular events more generally in patients with schizophrenia also highlight the role of shared risk factors that may raise the risk of both conditions independently (Osborn et al., 2015).

One difficulty in estimating the level of association between stroke and psychosis is that, as far as we are aware, all existing estimates have been drawn from clinical studies rather than population studies, meaning it is not clear to what extent estimates might be affected by selection biases, particularly referral bias. For example, all studies used to estimate prevalence of delusions and hallucinations in stroke patients included in the meta-analysis reported by Stangeland et al. (2018) were drawn from hospitalised stroke patients, potentially oversampling patients with the highest levels of disability.

This limitation is particularly important when trying to estimate the association between stroke and psychosis in low- and middle-income countries where specialised stroke care may be less available. Indeed, low- and middle-income countries proportionally show the highest levels of stroke incidence and poor outcome (Feigin et al., 2009; Johnson et al., 2019), raising the possibility of whether stroke and psychosis might be a more frequent combination in developing countries.

Consequently, in this study, we aimed to estimate the joint prevalence of stroke and psychosis and their statistical association using epidemiological studies from four countries. These included two high-income countries - the United Kingdom and the United States - and two middle-income countries - Chile and Colombia. Each of these countries have completed nationally representative psychiatric epidemiology studies that included structured assessments of psychotic disorders and / or psychotic symptoms, as well as measures of the participants' health, including stroke status. We subsequently combined all national datasets into a single dataset to estimate the association between stroke and psychosis across all four countries. 


\section{Methods}

\section{Datasets}

We used data from four nationally representative clinical epidemiological studies from the United Kingdom (UK), the United States of America (US), Chile and Colombia. Matched variables from across the four datasets were also merged to create a single combined countries dataset. The national datasets are described below.

\section{Adult Psychiatric Morbidity Survey 2007 (England, United Kingdom)}

The Adult Psychiatric Morbidity Survey (APMS) 2007 was a household survey that used a multi-stage stratified probability sampling to recruit participants. Using the English national postcode database, private households were identified, and any resident individual aged 16 years or over was invited to participate. If more than one individual aged over 16 years was resident, one adult was randomly chosen to ensure the same chance of being selected for all eligible individuals. Psychotic symptoms were measured using the Psychosis Screening Questionnaire (PSQ; Bebbington and Nayani, 1995). The PSQ is a 20-item interview that measures the presence of symptoms of hypomania, thought interference, persecution, perceptual abnormalities, strange experiences and hallucinosis. Full details of the survey and the sampling methods are reported in McManus et al. (2009).

\section{Collaborative Psychiatric Epidemiology Surveys 2001-2003 (United States)}

The Collaborative Psychiatric Epidemiology Surveys (CPES) consisted of the three nationally representative surveys of mental health in United States: the National Comorbidity Survey Replication (Kessler et al., 2004), the National Study of American Life (Jackson et al., 2004) and the National Latino and Asian American Study of Mental Health (Alegria et al., 2004). A two-component sampling method was used to recruit participants. The first involved a multistage stratified area probability design to derive a nationally representative household sample and the second involved high-density supplemental sampling to oversample specific ethnic groups (Afro-Caribbean, Chinese, Filipino, Vietnamese and Puerto Rican). Psychotic symptoms were measured using the World Health Organization Composite International Diagnostic Interview (WHO-CIDI) 3.0 Psychosis Screen (Kessler and Üstün, 2004) that measures the lifetime presence of six symptoms visual hallucinations, auditory hallucinations, thought insertion, thought control, delusions of reference, and persecutory delusions. Full details of the survey and sampling methods are reported in (Heeringa et al., 2004).

\section{National Mental Health Survey 2015 (Colombia)}

The National Mental Health Survey (NMHS) 2015 (Encuesta Nacional de Salud Mental) was a national survey of Colombia completed by the Ministry of Health and Social Protection (Ministerio de Salud y Protección Social). Participants were recruited using multistage stratified sampling that involved stratifying the population by region, municipality, and geographical area. Neighbourhood blocks in urban areas, and municipalities in rural areas were selected and all households were contacted for participation. Psychotic symptoms were measured using the WHO Self Reporting Questionnaire 24 (SRQ-24; Harding et al., 1980) which was deployed as an interview, rather than a self-completion questionnaire. The SRQ24 measures the presence of four psychotic symptoms: persecutory delusion, grandiosity, 
thought interference, and auditory hallucinations. Full details of the protocol and sampling methodology are reported in Gómez-Restrepo et al. (2016).

\section{National Health Survey 2016-2017 (Chile)}

The National Health Survey (NHS) 2016-2017 (Encuesta Nacional de Salud) was a national survey by the Chilean Ministry of Health of non-institutionalised individuals aged 15 years and older in households in urban and rural areas across 15 regions of Chile. Participants were identified using stratified multistage probability sampling. Psychotic symptoms were measured with the WHO-CIDI 3.0 Psychosis Screen (Kessler and Üstün, 2004). Full details of the survey and sampling methods are given in Ministerio de Salud (2017).

\section{Variable coding and missing data management}

Symptom data was recoded to represent strong evidence for the presence of symptoms. Where there was an ambiguous response data in response to interview questions about psychotic symptoms ('Unsure' responses in UK Adult Psychiatric Morbidity Survey; 'don't know' or 'didn't respond' responses in Chile National Health Survey) these were recoded as absent. Ambiguous responses were present at low rates: $0.4 \%$ of responses in the UK Adult Psychiatric Morbidity Survey data and $0.1 \%$ of the Chile National Health Survey data.

In the UK Adult Psychiatric Morbidity Survey, psychosis and stroke data was only collected after the participant responded 'yes' to initial screening questions, meaning missing data represented questions being intentionally not asked and therefore data was not missing at random. Consequently, the presence of stroke or psychotic symptoms was coded as not present for 'no' or 'item not applicable' data.

Missing data as originally present in the dataset is reported in Table 1. Notably, the majority of variables with missing data have low levels of missingness, below the threshold of 5\% considered to be likely to bias estimates (Jakobsen et al., 2017). However, the psychotic symptom data from the US Collaborative Psychiatric Epidemiology Surveys data showed higher levels of missingness (approximately 18\%). Random forest missing data imputation is highly reliable in reducing bias in estimates (Kokla et al., 2019; Shah et al., 2014). Consequently, the missing psychotic symptoms values were imputed using the missForest package for R (Stekhoven and Bühlmann, 2012). No additional instances of symptoms were imputed for the Collaborative Psychiatric Epidemiology Surveys data and so all missing variables were coded as 'not present'.

\section{Variables}

\section{Exposure}

In all studies, individuals were asked to report if they had been diagnosed with a stroke by a doctor during the structured health assessment. This was used as the primary exposure variable in regression analyses.

\section{Outcome}

Due to the use of differing psychosis measures across studies, we extracted data from symptom-level items that were designed to measure the following symptoms across all four studies: i) paranoia, ii) hallucinated voices, and iii) thought passivity delusion. 
There was no consistent measure of probable psychosis across surveys. The Adult Psychiatric Morbidity Survey and the Collaborative Psychiatric Epidemiology Surveys had inconsistent criteria (the former was based solely on symptom screening, the latter included service use i.e. antipsychotic, hospital admission) and the other surveys did not code for this category. Therefore, we created a standardised criteria for the category of 'probable psychosis' that was coded when any two psychotic symptoms were present. Consequently, probable psychosis was coded when a participant reported at least one delusion-like belief along with hallucinated voices, or at least two delusion-like beliefs at least one of which was a thoughtpassivity experience.

\section{Potential confounders}

We created a directed acyclic graph (Figure 1) using the $R$ package dagitty (Textor et al., 2016) of the likely causal structure of major risk factors linking stroke and psychosis based on evidenced associations to identify candidate covariates (Rohrer, 2018). Notably, analysis of the graph indicated that the total effect could not be estimated by covariate adjustment, largely due to the reciprocal causal relationship between stroke and psychosis and the role of alcohol and smoking, which act as mediators.

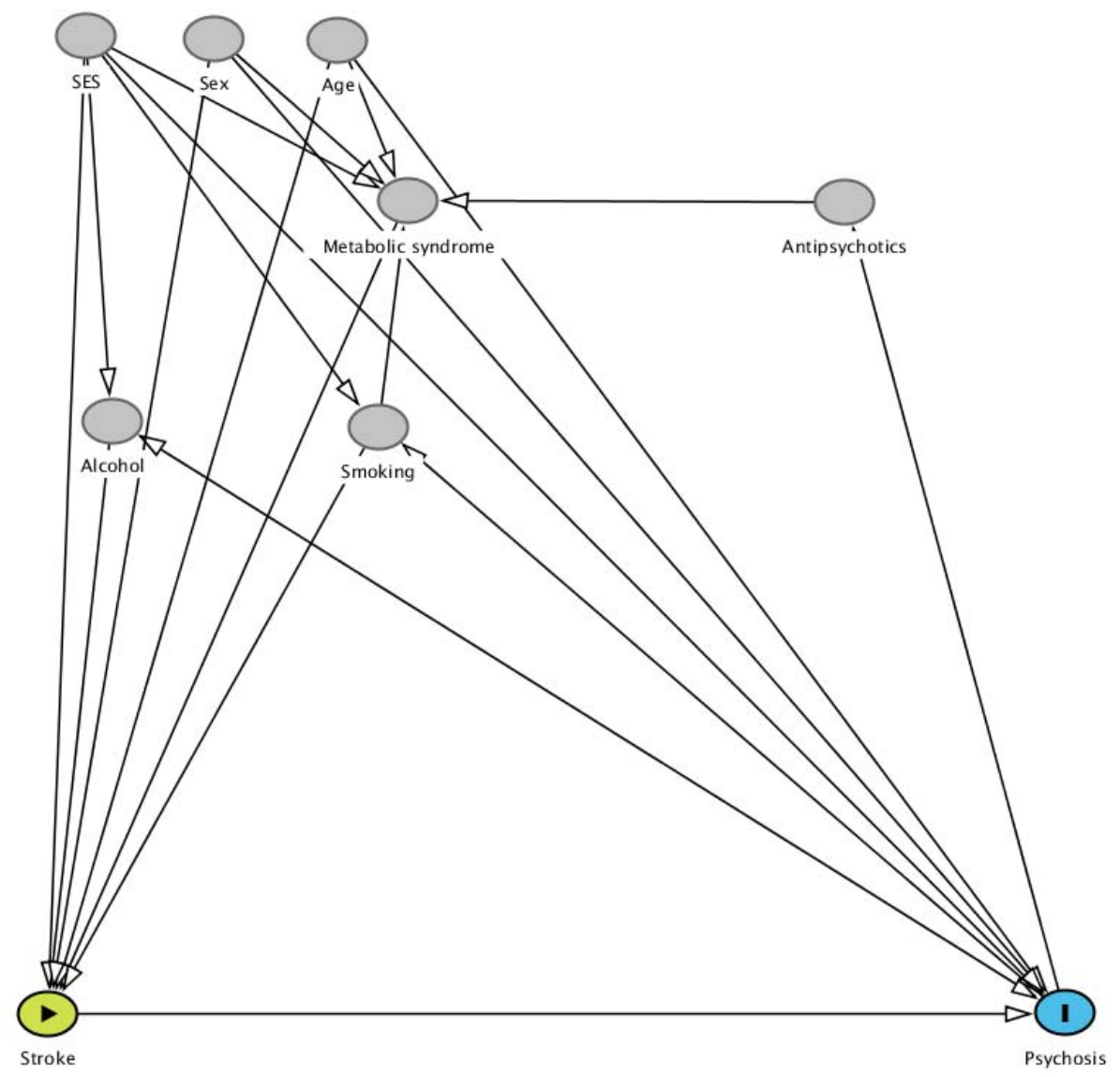

Figure 1. Directed acyclic graph of major causal relationships between stroke and psychosis 
Given this, we selected a minimal group of potential confounders that were most likely to represent pre-onset risk factors for both stroke and psychosis, namely age, sex, and highest level of education. Age and sex are independent predictors of stroke (Avan et al., 2019) and psychosis (Jongsma et al., 2019) before onset. There was no consistent measure of pre-onset socioeconomic status in all four studies. However, highest level of education, which correlates strongly with socioeconomic status and is frequently used as a component measure of it (Cox et al., 2006), is a pre-onset predictor of both stroke (Addo et al., 2012) and psychosis (Hakulinen et al., 2019), was included. Highest educational attainment was recoded across studies to a consistent coding of 'no or primary education only', 'mid-teen high school', 'late teen high school', and 'college / university'.

Both alcohol use and smoking are likely to be independent risk factors for both stroke (Pan et al., 2019; Reynolds et al., 2003) and psychosis (Jørgensen et al., 2018; Mustonen et al., 2018). However, there is also strong evidence for psychosis as a causal risk factor for smoking and alcohol use (Hartz et al., 2014), potentially indicating its additional role as a mediating factor. Furthermore, smoking and alcohol intake were only measured contemporaneously in the studies that reported them. Given these issues, alcohol and smoking were not included as potential confounders in the analysis.

\section{Analysis}

All analysis was conducted using $R$ version 4.03 (R Core Team, 2020) and the full code and output for the analysis is available in the format of a Jupyter Notebook (Rule et al., 2019), a document that combines both code and the output in a form that can be re-run and reproduced. All analysis code is available at the following link:

https://github.com/vaughanbell/stroke-psychosis-national-epi-analysis

\section{Prevalence}

We calculated the prevalence of stroke, prevalence of probable psychosis, prevalence of probable psychosis in people with stroke, and prevalence of stroke in people with probable psychosis using the epiR package (Stevenson et al., 2021). Prevalence and $95 \%$ confidence intervals were calculated for each of these for each individual national study and for the combined countries dataset.

\section{Association between stroke and psychosis}

At the national level, we used logistic regression models to estimate the association between stroke, probable psychosis, and individual psychotic symptoms (paranoia, hallucinated voices, passivity delusion).

We first estimated the unadjusted association and then the adjusted association - adjusted for sex, age, and highest level of education.

With the combined countries dataset, we completed a similar analysis but with multi-level regression models where country was added as a clustering variable to account for potential similarities within nations. 


\section{Results}

Descriptive statistics for each national survey and the combined dataset are reported in Table 1. The demographic profile was broadly similar across national surveys.

\begin{tabular}{|c|c|c|c|c|c|}
\hline & $\begin{array}{c}U K \\
(N=7403)\end{array}$ & $\begin{array}{c}\text { US } \\
(N=6082)\end{array}$ & $\begin{array}{c}\text { Colombia } \\
(N=10870)\end{array}$ & $\begin{array}{c}\text { Chile } \\
(N=3403)\end{array}$ & $\begin{array}{c}\text { Total } \\
(N=27758)\end{array}$ \\
\hline \multicolumn{6}{|l|}{ Age } \\
\hline Mean (SD) & $51.1(18.6)$ & $41.5(15.8)$ & $43.4(16.8)$ & $49.4(17.9)$ & $45.8(17.7)$ \\
\hline Median & 50.0 & 39.0 & 42.0 & 50.0 & 44.0 \\
\hline [Min, Max] & {$[16.0,95.0]$} & {$[18.0,99.0]$} & {$[18.0,96.0]$} & {$[17.0,98.0]$} & {$[16.0,99.0]$} \\
\hline \multicolumn{6}{|l|}{ Sex } \\
\hline Male & $3197(43.2 \%)$ & $2747(45.2 \%)$ & $4384(40.3 \%)$ & $1226(36.0 \%)$ & $11554(41.6 \%)$ \\
\hline Female & $4206(56.8 \%)$ & $3335(54.8 \%)$ & $6486(59.7 \%)$ & $2177(64.0 \%)$ & $16204(58.4 \%)$ \\
\hline \multicolumn{6}{|l|}{ Highest level of education } \\
\hline No / primary education & $2278(30.8 \%)$ & $540(8.9 \%)$ & $4007(36.9 \%)$ & $766(22.5 \%)$ & $7591(27.3 \%)$ \\
\hline Mid-teen high school & $2103(28.4 \%)$ & $835(13.7 \%)$ & $5152(47.4 \%)$ & $895(26.3 \%)$ & $8985(32.4 \%)$ \\
\hline Late teen high school & $938(12.7 \%)$ & $3604(59.3 \%)$ & $895(8.2 \%)$ & $1040(30.6 \%)$ & $6477(23.3 \%)$ \\
\hline College / university & $1916(25.9 \%)$ & $1103(18.1 \%)$ & $713(6.6 \%)$ & $668(19.6 \%)$ & $4400(15.9 \%)$ \\
\hline Missing & $168(2.3 \%)$ & $0(0 \%)$ & $103(0.9 \%)$ & $34(1.0 \%)$ & $305(1.1 \%)$ \\
\hline \multicolumn{6}{|l|}{ Stroke } \\
\hline Yes & $180(2.4 \%)$ & $171(2.8 \%)$ & $79(0.7 \%)$ & $95(2.8 \%)$ & 525 (1.9\%) \\
\hline No & $7223(97.6 \%)$ & $5724(94.1 \%)$ & $10791(99.3 \%)$ & $3287(96.6 \%)$ & 27025 (97.4\%) \\
\hline Missing & $0(0 \%)$ & $187(3.1 \%)$ & $0(0 \%)$ & $21(0.6 \%)$ & $208(0.7 \%)$ \\
\hline \multicolumn{6}{|l|}{ Paranoia } \\
\hline Yes & $569(7.7 \%)$ & $68(1.1 \%)$ & $2340(21.5 \%)$ & $59(1.7 \%)$ & $3036(10.9 \%)$ \\
\hline No & $6834(92.3 \%)$ & $4926(81.0 \%)$ & $8530(78.5 \%)$ & 3304 (97.1\%) & $23594(85.0 \%)$ \\
\hline Missing & $0(0 \%)$ & $1088(17.9 \%)$ & $0(0 \%)$ & $40(1.2 \%)$ & $1128(4.1 \%)$ \\
\hline \multicolumn{6}{|l|}{ Hallucinated voices } \\
\hline Yes & $68(0.9 \%)$ & $293(4.8 \%)$ & $362(3.3 \%)$ & $152(4.5 \%)$ & $875(3.2 \%)$ \\
\hline No & 7335 (99.1\%) & $4702(77.3 \%)$ & $10508(96.7 \%)$ & $3211(94.4 \%)$ & $25756(92.8 \%)$ \\
\hline Missing & $0(0 \%)$ & $1087(17.9 \%)$ & $0(0 \%)$ & $40(1.2 \%)$ & $1127(4.1 \%)$ \\
\hline \multicolumn{6}{|l|}{ Passivity delusion } \\
\hline Yes & $77(1.0 \%)$ & $33(0.5 \%)$ & 534 (4.9\%) & $18(0.5 \%)$ & $662(2.4 \%)$ \\
\hline No & $7326(99.0 \%)$ & $4962(81.6 \%)$ & $10336(95.1 \%)$ & 3345 (98.3\%) & $25969(93.6 \%)$ \\
\hline Missing & $0(0 \%)$ & $1087(17.9 \%)$ & $0(0 \%)$ & $40(1.2 \%)$ & $1127(4.1 \%)$ \\
\hline \multicolumn{6}{|l|}{ Probable Psychosis } \\
\hline Yes & $66(0.9 \%)$ & $36(0.6 \%)$ & $505(4.6 \%)$ & $27(0.8 \%)$ & $634(2.3 \%)$ \\
\hline No & $7337(99.1 \%)$ & $6046(99.4 \%)$ & $10365(95.4 \%)$ & $3376(99.2 \%)$ & $27124(97.7 \%)$ \\
\hline
\end{tabular}

Table 1. Descriptive statistics for national and combined datasets. 


\section{Prevalence}

Table 2 displays the calculated prevalence with $95 \%$ confidence intervals for stroke, probable psychosis, probable psychosis in stroke, and stroke in probable psychosis. The larger estimates of prevalence within national surveys tend to be accompanied by wider confidence intervals although the estimates for the combined countries dataset have consistently narrower confidence intervals, suggesting more reliable estimates.

\begin{tabular}{lcccc}
\hline & \multicolumn{4}{c}{ Prevalence (95\% CIs) } \\
\cline { 2 - 5 } & $\begin{array}{c}\text { Stroke in Total } \\
\text { Population }\end{array}$ & $\begin{array}{l}\text { Probable Psychosis } \\
\text { in Total Population }\end{array}$ & $\begin{array}{c}\text { Probable Psychosis in } \\
\text { Stroke Population }\end{array}$ & $\begin{array}{c}\text { Stroke in Probable } \\
\text { Psychosis Population }\end{array}$ \\
\hline United Kingdom & $2.43 \%(2.09-2.81)$ & $0.89 \%(0.69-1.13)$ & $1.11 \%(0.13-3.96)$ & $3.03 \%(0.37-10.52)$ \\
United States & $2.90 \%(2.49-3.36)$ & $0.59 \%(0.41-0.82)$ & $3.51 \%(1.30-7.48)$ & $16.67 \%(6.37-32.81)$ \\
Colombia & $0.73 \%(0.58-0.90)$ & $4.65 \%(4.26-5.06)$ & $13.92 \%(7.16-23.55)$ & $2.18 \%(1.09-3.86)$ \\
Chile & $2.81 \%(2.28-3.42)$ & $0.79 \%(0.52-1.15)$ & $1.05 \%(0.03-5.73)$ & $3.70 \%(0.09-18.97)$ \\
\hline Combined & $1.91 \%(1.75-2.07)$ & $2.28 \%(2.11-2.47)$ & $3.81 \%(2.34-5.82)$ & $3.15 \%(1.94-4.83)$ \\
\hline
\end{tabular}

Table 2. Prevalence and $95 \%$ confidence intervals $(\mathrm{Cls})$ for stroke, probable psychosis, probable psychosis in stroke, and stroke in probable psychosis across the four nations and combined country datasets

\section{Association and adjusted associations between stroke and psychosis}

Unadjusted associations between stroke and psychosis alongside associations adjusted for potential confounders are reported in Table 3. In addition, Table 4 reports unadjusted and adjusted associations for specific symptoms of psychosis.

\begin{tabular}{lcc}
\hline & \multicolumn{2}{c}{ Odds Ratios $(95 \%$ Cls $)$} \\
\cline { 2 - 3 } & \multicolumn{1}{c}{ Unadjusted } & Adjusted \\
\hline Probable Psychosis & $1.26(0.31-5.17)$ & $1.11(0.15-8.26)$ \\
United Kingdom & $6.90(2.83-16.81)$ & $6.22(2.52-15.35)$ \\
United States & $3.37(1.77-6.42)$ & $4.04(2.10-7.78)$ \\
Colombia & $1.33(0.18-9.94)$ & $1.33(0.18-10.09)$ \\
Chile & $3.06(1.93-4.85)$ & $3.32(2.05-5.38)$ \\
\hline Combined countries & &
\end{tabular}

Table 3. Results of unadjusted and adjusted logistic regression analysis reporting associations between stroke and probable psychosis with $95 \%$ confidence intervals (Cls) 
In the regression analyses, stroke does not reliably predict probable psychosis in the United Kingdom and Chile, although it is a reliable predictor in the United States, Colombia, and in the combined countries dataset.

\begin{tabular}{|c|c|c|}
\hline & \multicolumn{2}{|c|}{ Odds Ratios (95\% Cls) } \\
\hline & Unadjusted & Adjusted \\
\hline \multicolumn{3}{|l|}{ Paranoia } \\
\hline United Kingdom & $0.63(0.32-1.23)$ & $0.99(0.46-2.16)$ \\
\hline United States & $2.71(1.07-6.82)$ & $2.50(0.99-6.34)$ \\
\hline Colombia & $2.01(1.27-3.20)$ & $2.34(1.46-3.74)$ \\
\hline Chile & $1.92(0.59-6.26)$ & $1.71(0.52-5.66)$ \\
\hline Combined countries & $1.38(1.00-1.90)$ & $1.66(1.19-2.32)$ \\
\hline \multicolumn{3}{|l|}{ Hallucinated voices } \\
\hline United Kingdom & $0.60(0.08-4.32)$ & $0.85(0.11-6.29)$ \\
\hline United States & $2.33(1.41-3.86)$ & $2.03(1.22-3.38)$ \\
\hline Colombia & $4.30(2.20-8.41)$ & $4.06(2.05-8.03)$ \\
\hline Chile & $0.71(0.22-2.26)$ & $0.71(0.22-2.29)$ \\
\hline Combined countries & $2.01(1.39-2.90)$ & $1.89(1.30-2.74)$ \\
\hline \multicolumn{3}{|c|}{ Thought passivity delusion } \\
\hline United Kingdom & $1.07(0.26-4.40)$ & $0.67(0.09-4.94)$ \\
\hline United States & $2.17(0.52-9.16)$ & $2.12(0.50-9.00)$ \\
\hline Colombia & $3.52(1.89-6.55)$ & $4.27(2.27-8.03)$ \\
\hline Chile & $2.09(0.28-15.87)$ & $2.17(0.28-16.95)$ \\
\hline Combined countries & $2.51(1.52-4.14)$ & $2.68(1.59-4.52)$ \\
\hline
\end{tabular}

Table 4. Results of unadjusted and adjusted logistic regression analysis reporting associations between stroke and psychotic symptoms with $95 \%$ confidence intervals (Cls)

There is variation in the extent to which stroke is reliably associated with individual psychotic symptom measures across countries, although stroke is reliably associated with all symptoms in the combined countries dataset. 


\section{Discussion}

We report the joint prevalences of stroke and probable psychosis across four nationally representative epidemiological studies, and subsequently the association between stroke and probable psychosis after adjustment for potential confounders. We found that the prevalence of probable psychosis in people with stroke ranged from $1.05 \%$ (Chile) to $13.92 \%$ (Colombia) with the prevalence from the combined countries dataset estimated at $3.81 \%$. Conversely, the prevalence of stroke in people with probable psychosis ranged from $2.18 \%$ (Colombia) to $16.67 \%$ (US) with the combined countries prevalence estimated at $3.15 \%$. However, the larger estimates were accompanied by wide confidence intervals and are less likely to be accurate estimates of the population prevalence. Estimates for the adjusted association between stroke and probable psychosis ranged from an odds ratio of $1.11(95 \%$ CI 0.15 - 8.26) in the UK to an odds ratio of 6.22 in the US (95\% CIs 2.52 - 15.35) with the association from the combined dataset estimated at 3.32 (95\% CIs $2.05-5.38$ ). We also examined the association between stroke and paranoia, hallucinated voices, and thought passivity delusion, and although we found significant variation in the reliability and strength of association across countries, all three psychotic symptoms were associated with stroke in the unadjusted and adjusted analyses within the combined countries dataset.

This evidence suggests a relatively high co-prevalence of stroke and psychosis with approximately 1 in 26 people with stroke having probable psychosis and 1 in 32 of people with probable psychosis having stroke across the combined countries dataset. This is despite the fact that psychosis has often been described as a "rare" complication of stroke in the literature and has mostly been reported as single case studies or case series (e.g. Chemerinski and Robinson, 2000; Ferreira et al., 2017; Lo Buono et al., 2019). The estimate here is broadly in line with previous estimates of single psychotic symptoms in patients with stroke with meta-analytic estimates (admittedly from a small number of studies) suggesting a delusion prevalence of $4.67 \%$ and hallucination prevalence of $5.05 \%$ (Stangeland et al., 2018).

We also note that the majority of research in this area has focused on poststroke psychosis that likely contributes only a proportion of the co-prevalence of stroke and psychosis. As psychosis, and treatment for psychosis, is a risk factor for later stroke (Li et al., 2014; Marto et al., 2021), stroke in patients with a preceding history of psychosis is also likely to be an important contributory factor to co-prevalence. We also note here that initial studies report that patients with psychosis who later experience stroke have worse outcomes and are less likely to receive equitable care (Kisely et al., 2009; Willers et al., 2018) including timely invasive interventions (Nielsen et al., 2021). Taken together, this evidence suggests that stroke and psychosis may be highly disabling, but is under-recognised and likely underserved by existing services.

It is important to note that significant international variability was found in the estimates of association - either through calculating prevalence or odds ratios - between stroke and psychosis. Given the variability of measures used to measure psychotic symptoms within countries, one key question is the extent to which these estimates are being affected by 
characteristics of the measures, versus the extent to which the prevalence of psychotic symptoms and their association with stroke varies between countries.

We note two standout prevalence figures. A prevalence of probable psychosis in stroke of $13.92 \%$ in Colombia and a prevalence of stroke in probable psychosis of $16.67 \%$ in the US. Both of these figures have wide confidence intervals and the accompanying alternative prevalences (stroke in probable psychosis in Colombia, and probable psychosis in stroke in the US) are within the more typical ranges internationally. This suggests they may be less accurate estimates of the true prevalence. However, it remains challenging to separate measurement error from population-specific risk factors that contribute to these larger figures given the cross-sectional nature of the data.

For example, the estimated rate of probable psychosis in the total population is markedly higher in Colombia, which also has the highest estimated rate of probable psychosis in stroke. We note here that several factors may be important in influencing this outcome. The Colombia National Mental Health Survey used the WHO Self Reporting Questionnaire 24 (Harding et al., 1980), which although was deployed in an interview format, solely relied on participant answers without any judgment from the trained interviewers regarding the likelihood of the answer representing a symptom. Although self-report questionnaires for psychotic symptoms show broad agreement with interview measures they may over-report milder symptoms (Lincoln et al., 2010). We also note that, of the four counties included in this analysis, Colombia has the highest rate, and an internationally high rate, of violence and victimisation as well as experience of a long-running armed conflict (Institute for Economics $\&$ Peace, 2021). This likely contributes both to the over-rating of the paranoia item in terms of it measuring genuine threat rather than the exaggerated perception of threat, as well as likely increasing the rate of genuine paranoia as psychopathology, due to the fact that violent victimisation is associated with a higher risk of subsequent psychosis (Honings et al., 2017).

One potential way to interpret this data is to compare the extent to which the prevalence of probable psychosis used in this study compares to the prevalence of psychosis phenotypes. Here, our probable psychosis category as applied to the UK, US and Chile surveys are more likely to be measuring a narrow psychosis phenotype more akin to psychotic disorder, whereas in Colombia, it is more likely to be measuring a broader psychosis phenotype of psychotic experiences (van Os et al., 2009). However, it is also worth noting that in a recent systematic review of poststroke psychosis, delusional disorder, typically involving a single isolated delusion, was the most commonly reported psychosis in post-stroke cases - albeit from a relatively poor quality evidence base (Stangeland et al., 2018). The probable psychosis criteria used in this study would have excluded these cases, indicating that this may have underestimated the full prevalence of psychosis.

An additional factor is the extent to which stroke, psychosis, and their possible combination may be under-reported in community epidemiological studies due to a case ascertainment bias - in that those with more severe difficulties are less likely or less able to participate. Aked et al. (2020) compared stroke ascertainment between a community epidemiological study and a clinical register and reported that the community study was more likely to detect milder strokes but was equally likely to detect more severe cases. Nevertheless, the data used 
in the present study was from psychiatric epidemiology studies that require active participation in an extensive interview. Given this, it is likely that this may have led to an under-representation of more severe stroke or communication-impairing strokes in the dataset, and potentially, cases with more severe disability caused by a combination of stroke and psychosis.

We also note here that stroke was measured in all surveys by an interview item asking whether the person had been diagnosed with stroke by a doctor. Self-reported stroke has been found to have a consistently high negative predictive value but a variable positive predictive value (22-87\%) with the misreporting of transient ischaemic attacks for stroke likely to be a major contributor to false positive reporting (Woodfield et al., 2015). However, the measure used in this study was not self-reported stroke per se, but self-report of doctor-diagnosed stroke. As far as we are aware, the only study we know that has examined the accuracy of this specific method of reporting stroke was Walker et al. (1998) where self-report of doctordiagnosed stroke had a positive predictive value of 0.89 with the majority of false positive being reports of transient ischaemic attacks. Hence, the measure included in this study is most likely to represent both stroke proper and transient ischaemic attack. In addition, this measure is likely to be affected by the number of doctors available to diagnose stroke. This may underestimate prevalence in lower income countries where healthcare may be less accessible or inaccessible, or more likely to be carried out by non-physician healthcare professionals, particularly in remote or rural areas (World Health Organization, 2017). The lack of detail beyond the presence of absence of stroke also means it is not possible to make inferences regarding the relationship between stroke type, severity, location, recurrence and psychosis. Accordingly, studies using formal diagnosis and additional data on stroke characteristics are needed to ensure the highest accuracy of estimates and associations.

There are additional limitations that can should be noted. Due to the fact that this study uses cross-sectional data, the extent to which the association between stroke and psychosis consisted of poststroke psychosis, versus people with psychosis who later experienced stroke, was impossible to determine. This information is clearly important in developing both preventative healthcare and understanding how specific services (specifically psychiatry and neurology) should prioritise treatment and referral, given that the order of which psychosis or stroke occurs is likely to determine which service a patient has first contact with. Longitudinal studies will be needed to address these key questions. We also suggest that involvement of more integrated psychological medicine services in stroke services including both psychiatry and psychology is likely to be important, as is prioritising management of stroke risk factors in patients with psychosis (Barnett et al., 2007; Cooper et al., 2016). In addition, psychiatrists should be aware of the signs and symptoms of stroke, including apparently 'silent stroke' (Saini et al., 2012), and be aware of timely referral pathways to specialist stroke services in their area.

In conclusion, we report the first study on the association of stroke and psychosis in the general population that examines the co-prevalence and association within four countries: the US, UK, Colombia and Chile. We note that the conditions co-occur more frequently than has previously been assumed and there remains a marked lack of research in this area. This is a 
medRxiv preprint doi: https://doi.org/10.1101/2021.11.01.21265640; this version posted November 2, 2021. The copyright holder for this preprint (which was not certified by peer review) is the author/funder, who has granted medRxiv a license to display the preprint in perpetuity. It is made available under a CC-BY-NC-ND 4.0 International license .

particular priority given the potentially high need of these patient groups and the potential avoidance of stroke if risk factors are appropriately managed. Future research needs to involve standardised diagnostic assessments and longitudinal studies to determine the extent to which stroke and psychosis appear in specific causal sequences. 


\section{References}

Addo, J., Ayerbe, L., Mohan, K.M., Crichton, S., Sheldenkar, A., Chen, R., Wolfe, C.D.A., McKevitt, C., 2012. Socioeconomic Status and Stroke. Stroke 43, 1186-1191. https://doi.org/10.1161/STROKEAHA.111.639732

Aked, J., Delavaran, H., Norrving, B., Lindgren, A., 2020. Completeness of case ascertainment in Swedish hospital-based stroke registers. Acta Neurologica Scandinavica 141, 148-155. https://doi.org/10.1111/ane.13187

Alegria, M., Takeuchi, D., Canino, G., Duan, N., Shrout, P., Meng, X.-L., Vega, W., Zane, N., Vila, D., Woo, M., Vera, M., Guarnaccia, P., Aguilar-gaxiola, S., Sue, S., Escobar, J., Lin, K., Gong, F., 2004. Considering context, place and culture: the National Latino and Asian American Study. International Journal of Methods in Psychiatric Research 13, 208 220. https://doi.org/10.1002/mpr.178

Avan, A., Digaleh, H., Di Napoli, M., Stranges, S., Behrouz, R., Shojaeianbabaei, G., Amiri, A., Tabrizi, R., Mokhber, N., Spence, J.D., Azarpazhooh, M.R., 2019. Socioeconomic status and stroke incidence, prevalence, mortality, and worldwide burden: an ecological analysis from the Global Burden of Disease Study 2017. BMC Med 17, 191.

https://doi.org/10.1186/s12916-019-1397-3

Barnett, A.H., Mackin, P., Chaudhry, I., Farooqi, A., Gadsby, R., Heald, A., Hill, J., Millar, H., Peveler, R., Rees, A., Singh, V., TayLor, D., Vora, J., Jones, P.B., 2007. Minimising metabolic and cardiovascular risk in schizophrenia: diabetes, obesity and dyslipidaemia. J Psychopharmacol 21, 357-373. https://doi.org/10.1177/0269881107075509

Bebbington, P., Nayani, T., 1995. The Psychosis Screening Questionnaire. International Journal of Methods in Psychiatric research 5, 11-19.

Bresee, L.C., Majumdar, S.R., Patten, S.B., Johnson, J.A., 2010. Prevalence of cardiovascular risk factors and disease in people with schizophrenia: A population-based study.

Schizophrenia Research 117, 75-82. https://doi.org/10.1016/j.schres.2009.12.016

Charlson, F.J., Ferrari, A.J., Santomauro, D.F., Diminic, S., Stockings, E., Scott, J.G., McGrath, J.J., Whiteford, H.A., 2018. Global Epidemiology and Burden of Schizophrenia: Findings From the Global Burden of Disease Study 2016. Schizophrenia Bulletin 44, 11951203. https://doi.org/10.1093/schbul/sby058

Chemerinski, E., Robinson, R.G., 2000. The Neuropsychiatry of Stroke. Psychosomatics 41, 5-14. https://doi.org/10.1016/S0033-3182(00)71168-6

Cooper, S.J., Reynolds, G.P., Barnes, T., England, E., Haddad, P., Heald, A., Holt, R., Lingford-Hughes, A., Osborn, D., McGowan, O., Patel, M., Paton, C., Reid, P., Shiers, D., Smith, J., 2016. BAP guidelines on the management of weight gain, metabolic disturbances and cardiovascular risk associated with psychosis and antipsychotic drug treatment. J Psychopharmacol 30, 717-748. https://doi.org/10.1177/0269881116645254

Cox, A.M., McKevitt, C., Rudd, A.G., Wolfe, C.D., 2006. Socioeconomic status and stroke. The Lancet Neurology 5, 181-188. https://doi.org/10.1016/S1474-4422(06)70351-9 
Feigin, V.L., Lawes, C.M., Bennett, D.A., Barker-Collo, S.L., Parag, V., 2009. Worldwide stroke incidence and early case fatality reported in 56 population-based studies: a systematic review. The Lancet Neurology 8, 355-369. https://doi.org/10.1016/S1474-4422(09)70025-0

Ferreira, M. do C., Machado, C., Santos, B., Machado, Á., 2017. Post-stroke psychosis: how long should we treat? Trends Psychiatry Psychother. 39, 144-146.

https://doi.org/10.1590/2237-6089-2015-0090

Fleetwood, K., Wild, S.H., Smith, D.J., Mercer, S.W., Licence, K., Sudlow, C.L.M., Jackson, C.A., 2021. Association of severe mental illness with stroke outcomes and process-of-care quality indicators: nationwide cohort study. The British Journal of Psychiatry 1-8.

https://doi.org/10.1192/bjp.2021.120

Gómez-Restrepo, C., de Santacruz, C., Rodriguez, M.N., Rodriguez, V., Tamayo Martínez, N., Matallana, D., Gonzalez, L.M., 2016. Encuesta Nacional de Salud Mental Colombia 2015. Protocolo del estudio. Revista Colombiana de Psiquiatría, Encuesta Nacional de Salud Mental 2015 45, 2-8. https://doi.org/10.1016/j.rcp.2016.04.007

Hakulinen, C., McGrath, J.J., Timmerman, A., Skipper, N., Mortensen, P.B., Pedersen, C.B., Agerbo, E., 2019. The association between early-onset schizophrenia with employment, income, education, and cohabitation status: nationwide study with 35 years of follow-up. Soc Psychiatry Psychiatr Epidemiol 54, 1343-1351. https://doi.org/10.1007/s00127-019-01756-0

Harding, T.W., Arango, V.D., Baltazar, J., Climent, C.E., Ibrahim, H.H.A., Ladrido-Ignacio, L., Wig, N.N., 1980. Mental disorders in primary health care: a study of their frequency and diagnosis in four developing countries. Psychological Medicine 10, 231-241.

https://doi.org/10.1017/S0033291700043993

Hartz, S.M., Pato, C.N., Medeiros, H., Cavazos-Rehg, P., Sobell, J.L., Knowles, J.A., Bierut, L.J., Pato, M.T., for the Genomic Psychiatry Cohort Consortium, 2014. Comorbidity of Severe Psychotic Disorders With Measures of Substance Use. JAMA Psychiatry 71, 248254. https://doi.org/10.1001/jamapsychiatry.2013.3726

Heeringa, S.G., Wagner, J., Torres, M., Duan, N., Adams, T., Berglund, P., 2004. Sample designs and sampling methods for the Collaborative Psychiatric Epidemiology Studies (CPES). International Journal of Methods in Psychiatric Research 13, 221-240.

https://doi.org/10.1002/mpr.179

Honings, S., Drukker, M., ten Have, M., de Graaf, R., van Dorsselaer, S., van Os, J., 2017. The interplay of psychosis and victimisation across the life course: a prospective study in the general population. Soc Psychiatry Psychiatr Epidemiol 52, 1363-1374.

https://doi.org/10.1007/s00127-017-1430-9

Institute for Economics \& Peace, 2021. Global Peace Index 2021: Measuring Peace in a Complex World.

Jackson, J.S., Torres, M., Caldwell, C.H., Neighbors, H.W., Nesse, R.M., Taylor, R.J., Trierweiler, S.J., Williams, D.R., 2004. The National Survey of American Life: a study of racial, ethnic and cultural influences on mental disorders and mental health. International Journal of Methods in Psychiatric Research 13, 196-207. https://doi.org/10.1002/mpr.177 
Jakobsen, J.C., Gluud, C., Wetterslev, J., Winkel, P., 2017. When and how should multiple imputation be used for handling missing data in randomised clinical trials - a practical guide with flowcharts. BMC Medical Research Methodology 17, 162.

https://doi.org/10.1186/s12874-017-0442-1

Johnson, C.O., Nguyen, M., Roth, G.A., Nichols, E., Alam, T., Abate, D., Abd-Allah, F., Abdelalim, A., Abraha, H.N., Abu-Rmeileh, N.M., Adebayo, O.M., Adeoye, A.M., Agarwal, G., Agrawal, S., Aichour, A.N., Aichour, I., Aichour, M.T.E., Alahdab, F., Ali, R., AlvisGuzman, N., Anber, N.H., Anjomshoa, M., Arabloo, J., Arauz, A., Ärnlöv, J., Arora, A., Awasthi, A., Banach, M., Barboza, M.A., Barker-Collo, S.L., Bärnighausen, T.W., Basu, S., Belachew, A.B., Belayneh, Y.M., Bennett, D.A., Bensenor, I.M., Bhattacharyya, K., Biadgo, B., Bijani, A., Bikbov, B., Sayeed, M.S.B., Butt, Z.A., Cahuana-Hurtado, L., Carrero, J.J., Carvalho, F., Castañeda-Orjuela, C.A., Castro, F., Catalá-López, F., Chaiah, Y., Chiang, P.P.C., Choi, J.-Y.J., Christensen, H., Chu, D.-T., Cortinovis, M., Damasceno, A.A.M., Dandona, L., Dandona, R., Daryani, A., Davletov, K., Courten, B. de, Cruz-Góngora, V.D. la, Degefa, M.G., Dharmaratne, S.D., Diaz, D., Dubey, M., Duken, E.E., Edessa, D., Endres, M., Faraon, E.J.A., Farzadfar, F., Fernandes, E., Fischer, F., Flor, L.S., Ganji, M., Gebre, A.K., Gebremichael, T.G., Geta, B., Gezae, K.E., Gill, P.S., Gnedovskaya, E.V., Gómez-Dantés, H., Goulart, A.C., Grosso, G., Guo, Y., Gupta, R., Haj-Mirzaian, Arvin, Haj-Mirzaian, Arya, Hamidi, S., Hankey, G.J., Hassen, H.Y., Hay, S.I., Hegazy, M.I., Heidari, B., Herial, N.A., Hosseini, M.A., Hostiuc, S., Irvani, S.S.N., Islam, S.M.S., Jahanmehr, N., Javanbakht, M., Jha, R.P., Jonas, J.B., Jozwiak, J.J., Jürisson, M., Kahsay, A., Kalani, R., Kalkonde, Y., Kamil, T.A., Kanchan, T., Karch, A., Karimi, N., Karimi-Sari, H., Kasaeian, A., Kassa, T.D., Kazemeini, H., Kefale, A.T., Khader, Y.S., Khalil, I.A., Khan, E.A., Khang, Y.-H., Khubchandani, J., Kim, D., Kim, Y.J., Kisa, A., Kivimäki, M., Koyanagi, A., Krishnamurthi, R.K., Kumar, G.A., Lafranconi, A., Lewington, S., Li, S., Lo, W.D., Lopez, A.D., Lorkowski, S., Lotufo, P.A., Mackay, M.T., Majdan, M., Majdzadeh, R., Majeed, A., Malekzadeh, R., Manafi, N., Mansournia, M.A., Mehndiratta, M.M., Mehta, V., Mengistu, G., Meretoja, A., Meretoja, T.J., Miazgowski, B., Miazgowski, T., Miller, T.R., Mirrakhimov, E.M., Mohajer, B., Mohammad, Y., Mohammadoo-khorasani, M., Mohammed, S., Mohebi, F., Mokdad, A.H., Mokhayeri, Y., Moradi, G., Morawska, L., Velásquez, I.M., Mousavi, S.M., Muhammed, O.S.S., Muruet, W., Naderi, M., Naghavi, M., Naik, G., Nascimento, B.R., Negoi, R.I., Nguyen, C.T., Nguyen, L.H., Nirayo, Y.L., Norrving, B., Noubiap, J.J., OforiAsenso, R., Ogbo, F.A., Olagunju, A.T., Olagunju, T.O., Owolabi, M.O., Pandian, J.D., Patel, S., Perico, N., Piradov, M.A., Polinder, S., Postma, M.J., Poustchi, H., Prakash, V., Qorbani, M., Rafiei, A., Rahim, F., Rahimi, K., Rahimi-Movaghar, V., Rahman, M., Rahman, M.A., Reis, C., Remuzzi, G., Renzaho, A.M.N., Ricci, S., Roberts, N.L.S., Robinson, S.R., Roever, L., Roshandel, G., Sabbagh, P., Safari, H., Safari, S., Safiri, S., Sahebkar, A., Zahabi, S.S., Samy, A.M., Santalucia, P., Santos, I.S., Santos, J.V., Milicevic, M.M.S., Sartorius, B., Sawant, A.R., Schutte, A.E., Sepanlou, S.G., Shafieesabet, A., Shaikh, M.A., Shams-Beyranvand, M., Sheikh, A., Sheth, K.N., Shibuya, K., Shigematsu, M., Shin, M.-J., Shiue, I., Siabani, S., Sobaih, B.H., Sposato, L.A., Sutradhar, I., Sylaja, P.N., Szoeke, C.E.I., Ao, B.J.T., Temsah, M.-H., Temsah, O., Thrift, A.G., Tonelli, M., Topor-Madry, R., Tran, B.X., Tran, K.B., Truelsen, T.C., Tsadik, A.G., Ullah, I., Uthman, O.A., Vaduganathan, M., Valdez, P.R., Vasankari, T.J., Vasanthan, R., Venketasubramanian, N., Vosoughi, K., Vu, G.T., Waheed, Y., Weiderpass, E., Weldegwergs, K.G., Westerman, R., Wolfe, C.D.A., Wondafrash, D.Z., Xu, G., Yadollahpour, A., Yamada, T., Yatsuya, H., Yimer, E.M., 
Yonemoto, N., Yousefifard, M., Yu, C., Zaidi, Z., Zamani, M., Zarghi, A., Zhang, Y., Zodpey, S., Feigin, V.L., Vos, T., Murray, C.J.L., 2019. Global, regional, and national burden of stroke, 1990-2016: a systematic analysis for the Global Burden of Disease Study 2016. The Lancet Neurology 18, 439-458. https://doi.org/10.1016/S1474-4422(19)30034-1

Jongsma, H.E., Turner, C., Kirkbride, J.B., Jones, P.B., 2019. International incidence of psychotic disorders, 2002-17: a systematic review and meta-analysis. The Lancet Public Health 4, e229-e244. https://doi.org/10.1016/S2468-2667(19)30056-8

Jørgensen, K.B., Nordentoft, M., Hjorthøj, C., 2018. Association between alcohol and substance use disorders and psychiatric service use in patients with severe mental illness: a nationwide Danish register-based cohort study. Psychological Medicine 48, 2592-2600. https://doi.org/10.1017/S0033291718000223

Kessler, R.C., Berglund, P., Chiu, W.T., Demler, O., Heeringa, S., Hiripi, E., Jin, R., Pennell, B.-E., Walters, E.E., Zaslavsky, A., Zheng, H., 2004. The US National Comorbidity Survey Replication (NCS-R): design and field procedures. International Journal of Methods in Psychiatric Research 13, 69-92. https://doi.org/10.1002/mpr.167

Kessler, R.C., Üstün, T.B., 2004. The World Mental Health (WMH) Survey Initiative version of the World Health Organization (WHO) Composite International Diagnostic Interview (CIDI). International Journal of Methods in Psychiatric Research 13, 93-121. https://doi.org/10.1002/mpr.168

Kisely, S., Campbell, L.A., Wang, Y., 2009. Treatment of ischaemic heart disease and stroke in individuals with psychosis under universal healthcare. The British Journal of Psychiatry 195, 545-550. https://doi.org/10.1192/bjp.bp.109.067082

Kokla, M., Virtanen, J., Kolehmainen, M., Paananen, J., Hanhineva, K., 2019. Random forest-based imputation outperforms other methods for imputing LC-MS metabolomics data: a comparative study. BMC Bioinformatics 20, 492. https://doi.org/10.1186/s12859-019-31100

Li, M., Fan, Y.-L., Tang, Z.-Y., Cheng, X.-S., 2014. Schizophrenia and risk of stroke: A meta-analysis of cohort studies. International Journal of Cardiology 173, 588-590. https://doi.org/10.1016/j.ijcard.2014.03.101

Lincoln, T.M., Ziegler, M., Lüllmann, E., Müller, M.J., Rief, W., 2010. Can delusions be self-assessed? Concordance between self- and observer-rated delusions in schizophrenia. Psychiatry Research 178, 249-254. https://doi.org/10.1016/j.psychres.2009.04.019

Lo Buono, V., Corallo, F., Allone, C., Bonanno, L., Sessa, E., Todaro, A., Pidalà, A., Bramanti, A., Marino, S., 2019. Thought disorder in atypical schizophrenia-like psychosis after stroke: analysis of clinical cases. Neurocase 25, 130-132. https://doi.org/10.1080/13554794.2019.1623266

Marto, J.P., Strambo, D., Livio, F., Michel, P., 2021. Drugs Associated With Ischemic Stroke. Stroke 52, e646-e659. https://doi.org/10.1161/STROKEAHA.120.033272

McManus, S., Meltzer, H., Brugha, T., Bebbington, P.E., Jenkins, R., 2009. Adult psychiatric morbidity in England: Results of a household survey. Health and Social Care Information Centre. 
Ministerio de Salud, 2017. ENCUESTA NACIONAL DE SALUD 2016-2017 Primeros resultados.

Mustonen, A., Ahokas, T., Nordström, T., Murray, G.K., Mäki, P., Jääskeläinen, E., Heiskala, A., Mcgrath, J.J., Scott, J.G., Miettunen, J., Niemelä, S., 2018. Smokin` hot: adolescent smoking and the risk of psychosis. Acta Psychiatrica Scandinavica 138, 5-14. https://doi.org/10.1111/acps.12863

Nielsen, R.E., Banner, J., Jensen, S.E., 2021. Cardiovascular disease in patients with severe mental illness. Nat Rev Cardiol 18, 136-145. https://doi.org/10.1038/s41569-020-00463-7

Osborn, D.P.J., Hardoon, S., Omar, R.Z., Holt, R.I.G., King, M., Larsen, J., Marston, L., Morris, R.W., Nazareth, I., Walters, K., Petersen, I., 2015. Cardiovascular Risk Prediction Models for People With Severe Mental Illness: Results From the Prediction and Management of Cardiovascular Risk in People With Severe Mental Illnesses (PRIMROSE) Research Program. JAMA Psychiatry 72, 143-151. https://doi.org/10.1001/jamapsychiatry.2014.2133

Pan, B., Jin, X., Jun, L., Qiu, S., Zheng, Q., Pan, M., 2019. The relationship between smoking and stroke. Medicine (Baltimore) 98, e14872.

https://doi.org/10.1097/MD.0000000000014872

R Core Team, 2020. R: A language and environment for statistical computing. R Foundation for Statistical Computing, Vienna, Austria.

Reynolds, K., Lewis, B., Nolen, J.D.L., Kinney, G.L., Sathya, B., He, J., 2003. Alcohol Consumption and Risk of Stroke: A Meta-analysis. JAMA 289, 579-588.

https://doi.org/10.1001/jama.289.5.579

Rohrer, J.M., 2018. Thinking Clearly About Correlations and Causation: Graphical Causal Models for Observational Data. Advances in Methods and Practices in Psychological Science 1, 27-42. https://doi.org/10.1177/2515245917745629

Rule, A., Birmingham, A., Zuniga, C., Altintas, I., Huang, S.-C., Knight, R., Moshiri, N., Nguyen, M.H., Rosenthal, S.B., Pérez, F., Rose, P.W., 2019. Ten simple rules for writing and sharing computational analyses in Jupyter Notebooks. PLOS Computational Biology 15, e1007007. https://doi.org/10.1371/journal.pcbi.1007007

Saini, M., Ikram, K., Hilal, S., Qiu, A., Venketasubramanian, N., Chen, C., 2012. Silent Stroke. Stroke 43, 3102-3104. https://doi.org/10.1161/STROKEAHA.112.666461

Shah, A.D., Bartlett, J.W., Carpenter, J., Nicholas, O., Hemingway, H., 2014. Comparison of Random Forest and Parametric Imputation Models for Imputing Missing Data Using MICE: A CALIBER Study. American Journal of Epidemiology 179, 764-774. https://doi.org/10.1093/aje/kwt312

Stangeland, H., Orgeta, V., Bell, V., 2018. Poststroke psychosis: a systematic review. J Neurol Neurosurg Psychiatry 89, 879-885. https://doi.org/10.1136/jnnp-2017-317327

Stekhoven, D.J., Bühlmann, P., 2012. MissForest-non-parametric missing value imputation for mixed-type data. Bioinformatics 28, 112-118. https://doi.org/10.1093/bioinformatics/btr597 
Stevenson, M., Nunes, T., Sanchez, J., Thornton, R., Reiczigel, J., Robison-Cox, J., Sebastiani, P., Solymos, P., Yoshida, K., Jones, G., 2021. epiR: An R package for the analysis of epidemiological data. R package version 2.0.31. Vienna, Austria: R Foundation for Statistical Computing.

Su, C.-C., Yang, Y.-H.K., Lai, E.C.-C., Hsieh, C.-Y., Cheng, C.-L., Chen, C.-H., Lin, H.-J., Sung, S.-F., Chen, Y.-W., 2021. Comparative safety of antipsychotic medications in elderly stroke survivors: A nationwide claim data and stroke registry linkage cohort study. Journal of Psychiatric Research 139, 159-166. https://doi.org/10.1016/j.jpsychires.2021.05.025

Textor, J., van der Zander, B., Gilthorpe, M.S., Liśkiewicz, M., Ellison, G.T., 2016. Robust causal inference using directed acyclic graphs: the R package 'dagitty.' International Journal of Epidemiology 45, 1887-1894. https://doi.org/10.1093/ije/dyw341

van Os, J., Linscott, R.J., Myin-Germeys, I., Delespaul, P., Krabbendam, L., 2009. A systematic review and meta-analysis of the psychosis continuum: evidence for a psychosis proneness-persistence-impairment model of psychotic disorder. Psychological Medicine 39, 179-195. https://doi.org/10.1017/S0033291708003814

Walker, M.K., Whincup, P.H., Shaper, A.G., Lennon, L.T., Thomson, A.G., 1998. Validation of Patient Recall of Doctor-diagnosed Heart Attack and Stroke: A Postal Questionnaire and Record Review Comparison. American Journal of Epidemiology 148, 355-361.

https://doi.org/10.1093/oxfordjournals.aje.a009653

Willers, C., Sunnerhagen, K.S., Lekander, I., von Euler, M., 2018. The Association of Prestroke Psychosis and Post-stroke Levels of Health, Resource Utilization, and Care Process: A Register-Based Study. Frontiers in Neurology 9, 1042.

https://doi.org/10.3389/fneur.2018.01042

Woodfield, R., Group, U.B.S.O., Group, U.B.F. and O.W., Sudlow, C.L.M., 2015. Accuracy of Patient Self-Report of Stroke: A Systematic Review from the UK Biobank Stroke Outcomes Group. PLOS ONE 10, e0137538. https://doi.org/10.1371/journal.pone.0137538

World Health Organization, 2017. Tracking universal health coverage: 2017 global monitoring report. World Health Organization. 